\title{
Detección de bassianolida y beauvericina en cepas de Beauveria bassiana y su participación en la actividad patogénica hacia Spodoptera sp.
}

\author{
Bassianolide and beauvericin detection in Beauveria bassiana strains and their participation in the \\ pathogenic activity against Spodoptera sp.
}

Ninfa M. Rosas-García*, Maribel Mireles-Martínez, Jesús Manuel Villegas-Mendoza

Laboratorio de Biotecnología Ambiental, Centro de Biotecnología Genómica, Instituto Politécnico Nacional. Blvd. del Maestro s/n esq. Elías Piña Col. Narciso Mendoza, CP 88710, Reynosa, Tamaulipas, México.

\section{RESUMEN}

Beauveria bassiana es un hongo entomopatógeno que produce metabolitos secundarios como factores de virulencia durante el proceso patogénico en insectos. En este estudio se analizaron once cepas de B. bassiana para determinar la presencia de los genes bbBeas y bbBs/s productores de los depsipéptidos ciclooligoméricos no ribosomales beauvericina y bassianolida, respectivamente. Los genes fueron caracterizados por PCR y secuenciación. La presencia de beauvericina y bassianolida en extractos de micelio se determinó por espectrometría de masas. Los resultados indicaron que con excepción de la cepa 2857, todas poseen los dos genes y sintetizan bassianolida. En ningún caso se produjo la beauvericina. La mortalidad por conidias en larvas de Spodoptera exigua y $S$. frugiperda fue variable, pero las cepas 1512, 2253 y 2857 causaron las mayores mortalidades (44\% en promedio). El extracto con bassianolida inyectado $(1 \mathrm{mg} / \mathrm{mL}$ ) causó $26 \%$ de mortalidad en larvas de S. exigua. La falta de producción de beauvericina, con excepción de la cepa 1149, puede deberse al requerimiento de otro tipo de condiciones de cultivo que estimulen la expresión de los genes. Hasta ahora no se observa correlación entre la actividad patogénica del hongo y la presencia o ausencia de estos metabolitos secundarios.

Palabras clave. Péptidos bioactivos, Metabolito secundario, Entomopatógeno, Insecto plaga.

\section{ABSTRACT}

Beauveria bassiana is an entomopathogenic fungus that produces secondary metabolites as virulence factors during the pathogenic process in insects. In this study, eleven strains of $B$. bassiana were analyzed to determine the presence of the bbBeas and $b b B s / s$ genes that produce beauvericin and bassianolide non-ribosomal cyclooligomeric depsypeptides, respectively. The genes were characterized by PCR and DNA sequencing. The presence of beauvericin and bassianolide from mycelial extracts were determined by mass spectrometry. The results indicated that with the exception of strain 2857, they all possess both genes and synthesized bassianolide. Beauvericin was not produced in any case. Mortality caused by conidia in Spodoptera exigua and S. frugiperda neonate larvae was variable. Strains 1512, 2253 and 2857 caused significantly higher mortalities (44\% mortality on average). The bassianolide extract injected (1 $\mathrm{mg} / \mathrm{mL}$ ) caused $26 \%$ mortality in S. exigua. The lack of beauvericin production, with the exception of strain 1149, may be due to the requirement of other culture conditions that stimulate the expression of the genes. So far, no correlation is observed between the pathogenic activity of the fungus, and the presence or absence of these secondary metabolites. Keywords. Bioactive peptides, Secondary metabolite, Entomopathogen, Insect pest.

\section{INTRODUCCIÓN}

El hongo Beauveria bassiana, descubierto por Agostino Bassi de Lodi en las larvas del gusano de seda en 1835, es un entomopatógeno cosmopolita con un amplísimo rango de hospederos (Singh et al., 2015). Este hongo pertenece a la familia de los Hypocreales y su estado teleomórfico es Cordyceps bassiana. La patogénesis que B. bassiana causa en el insecto inicia por la unión de las conidias a la cutícula del hospedero, éstas germinan y penetran para invadir el hemocele. El insecto hospedero muere debido al agotamiento de la hemolinfa causado por la invasión del hongo, así como por una toxemia causada por la producción de metabolitos tóxicos fúngicos. La bassianolida y la beauvericina forman parte de los diversos metabolitos secundarios que produce este hongo y a los cuales se les han atribuido actividades tóxicas contra insectos (Feng et al., 1994; Molnár et al., 2010). Estos compuestos son péptidos bioactivos producidos de manera no ribosomal por grandes complejos enzimáticos multiméricos llamados sintetasas peptídicas no ribosomales (NRPSs por sus siglas en inglés), cuyos módulos funcionales utilizan tres dominios centrales denominados: Adenilación, Tiolación y Condensación. La beauvericina es un trímero de éster cíclico de monómeros de dipeptidol formado por (2R)-2-hidroxi-3-ácido metil butanoico (ácido D-hidroxiisovalérico, D-Hiv) y N-metil-L-fenilalanina (N-MePhe) (Xu et al., 2008). La bassianolida es un octadepsipéptido con un anillo de macrolactona de 24 miembros que está formado como un éster tetramérico cíclico del monómero dipeptidol D-hidroxiisovalerato. Estos genes se encuentran en clusters asociados con factores de transcripción específicos y genes de enzimas modificadoras, y debido a que el uso de esta maquinaria biosintética es energéticamente costosa, su producción sugiere una ventaja de supervivencia al orga- 
nismo, porque su activación ocurre solamente en presencia de estrés ambiental o de una íntima exposición a otros organismos (Gibson et al., 2014). Tanto a la beauvericina como a la bassianolida se les ha atribuido una participación como factores de virulencia en el proceso patogénico en insectos; sin embargo, son pocos los estudios que arrojan información sobre este aspecto y la actividad reportada es variable, por lo tanto el objetivo de este trabajo es detectar molecularmente la presencia de los genes bbBeas y bbBsls productores de la beauvericina y bassianolida respectivamente, en cepas de $B$. bassiana y la participación de estos metabolitos en el proceso patógenico en larvas de Spodoptera exigua y S. frugiperda.

\section{MÉTODOS Y MATERIALES Material biológico}

Las cepas de B. bassiana 3289, 1118, 1149, 1315, 1512, 1627, 2253, 2857, 3288, 5649 y 3019 fueron proporcionadas por la Collection of Entomopathogenic fungal cultures (ARSEF) USDA-ARS BiolPM Research Unit (Ithaca, NY). Las cepas fueron seleccionadas en base a su actividad patogénica contra lepidópteros y se mantuvieron en agar papa dextrosa hasta su uso. Las cepas Bb1, Bb2, Bb3, Bb4 son cepas nativas de la colección del Laboratorio de Biotecnología Ambiental CBG-IPN y se utilizaron como controles en los bioensayos. La cepa GHA, también utilizada como control fue proporcionada amablemente por el Dr. Stefan Jaronski. Las larvas de $S$. exigua y $S$. frugiperda se obtuvieron de colonias alimentadas con dieta artificial (Tabla 1) y mantenidas a $25{ }^{\circ} \mathrm{C} \pm 1{ }^{\circ} \mathrm{C}$, fotoperiodo de 14:10 h (luz:oscuridad), $65 \% \pm 1 \%$ humedad relativa en el área de cría de insectos del Laboratorio de Biotecnología Ambiental CBG-IPN.

\section{Análisis por PCR y secuenciación}

Para determinar la presencia de las secuencias homólogas del dominio A se utilizó el DNA total de las cepas de B. bassiana siguiendo el protocolo de Raeder y Broda

Tabla 1. Ingredientes para la dieta artificial de Spodoptera frugiperda.

Table 1. Ingredients for Spodoptera frugiperda artificial diet.

\begin{tabular}{lc}
\hline Ingredientes & Cantidad (g/L) \\
\hline Harina de soya & 71.1 \\
\hline Germen de trigo & 31.7 \\
Levadura & 40 \\
\hline Agar & 10 \\
Sales Wesson & 10 \\
\hline Cloruro de colina & 2 \\
\hline Ácido ascórbico & 4 \\
\hline Ácido sórbico & 2 \\
\hline Metilparaben & 2.5 \\
\hline Mezcla vitamínica Vanderzant & 2 \\
\hline
\end{tabular}

Disolver el agar en agua hirviendo y mezclar con todos los ingredientes sólidos en una licuadora por 10 min; posteriormente, agregar los ingredientes líquidos y mezclar por $5 \mathrm{~min}$. La mezcla vitamínica se añade al final y se mezcla por $2 \mathrm{~min}$. Vaciar la dieta en los recipientes inmediatamente.
(1985). Para la amplificación por PCR se utilizaron los oligonucleótidos EA1F (5'-TATGTCATCTTCACCTCGGG-3') y EA1R (5'-TGACCTGGGAGTCCATACGG-3') reportados por Xu et al. (2009b) y que están basados en los motivos A3 y A8 del dominio A que incorpora el ácido D-hidroxiisovalérico (D-Hiv) de la enniatina sintetasa de Fusarium equiseti. Las condiciones de reacción fueron de: $12.5 \mu \mathrm{L}$ de GoTaq Green Master Mix (1X), $3.75 \mu \mathrm{L}$ de cada oligonucleótido $(0.75 \mu \mathrm{M}), 1 \mu \mathrm{L}$ de DNAg a un volumen final de $25 \mu \mathrm{L}$. La amplificación se realizó en un equipo termociclador SimpliAmp ${ }^{\circledR}$ (Themo Fisher Scientific, Waltham MA, USA) con las siguientes condiciones de reacción: $94^{\circ} \mathrm{C} / 2$ min; seguido de 35 ciclos de $94^{\circ} \mathrm{C} / 30 \mathrm{~s}, 60^{\circ} \mathrm{C} / 30$ $\mathrm{s}, 72^{\circ} \mathrm{C} / 1 \mathrm{~min} ; \mathrm{y}$ un paso de extensión final de $72^{\circ} \mathrm{C} / 5 \mathrm{~min}$. Los productos de la reacción se colocaron en un gel de agarosa al $1.5 \%$, y la electroforesis se corrió a $80 \mathrm{~V} / 1$ h. Para la detección específica de los genes BbBEAS y $b b B s / s$ se realizaron PCR anidadas utilizando los oligonucleótidos reportados por Xu et al. (2009b), Ea1046 (EA1046f: 5'-TCATGATTGAGCATCAAGCG-3'; EA1046r: 5'-CTTGCCAATGAAACAGATGG-3') para bbBeas y Ea1042 (EA1042f: 5'-CTTCTGTTGTCAAGTTTGGCAAGG-3'; EA1042r: 5'GCTT TCTATGAGTAGCTCGCCAAT-3') para bbBs/s de manera independiente y con las condiciones descritas anteriormente. Para el proceso de secuenciación se seleccionaron dos cepas de $B$. bassiana. Los primers utilizados para la secuenciación fueron ITS1-Fwd (5'-TCCGTAGGTGAACCTGCGG-3') e ITS4-Rev (5'-TCCTCCGCTTATTATTGATATGC-3'). La reacción de PCR se llevó a cabo con $12.5 \mu \mathrm{L}$ de GoTaq Green Master Mix, $1 \mu \mathrm{L}$ de primer $(5 \mu \mathrm{M}), 50$ ng de DNA genómico, en un volumen final de reacción de $25 \mu \mathrm{L}$. Las condiciones de amplificación fueron: un paso de desnaturalización a 94 ${ }^{\circ} \mathrm{C}$ por 5 min, 35 ciclos con un paso de desnaturalización a $95{ }^{\circ} \mathrm{C}$ por $30 \mathrm{~s}$, alineamiento a $58^{\circ} \mathrm{C}$ por $30 \mathrm{~s}$, extensión a 72 ${ }^{\circ} \mathrm{C}$ por $1 \mathrm{~min}$, y un paso de extensión final a $72{ }^{\circ} \mathrm{C}$ por $7 \mathrm{~min}$. Los productos de PCR se separaron por electroforesis en gel de agarosa al $1.5 \%$ y los fragmentos de 700 pb fueron seleccionados y purificados con ExoSAP-IT. Para la secuenciación se utilizó el BigDye ${ }^{\circledR}$ Terminator v3.1 Cycle Sequencing Kit. El análisis se llevó a cabo en un secuenciador System 3130 Genetic Analyzer (Themo Fisher Scientific, Waltham MA, USA). Las secuencias se ensamblaron con el software SeqMan de la suite Lasergene Genomics y se compararon con las secuencias depositadas en el GenBank.

\section{Obtención del extracto}

Para la producción de los metabolitos y obtención del extracto, cada cepa se cultivó en diez matraces de $500 \mathrm{~mL}$ con $100 \mathrm{~mL}$ de caldo papa dextrosa en un agitador rotatorio a $160 \mathrm{rpm}$ y $28^{\circ} \mathrm{C}$ por tres días. Los cultivos se filtraron con papel Whatman No. 1, y el paquete micelial recuperado se sumergió en metanol durante siete días (Xu et al., 2007). Posteriormente el micelio se filtró nuevamente y el sobrenadante se descartó ya que contiene menos del $1 \%$ de los compuestos. El filtrado se concentró bajo presión reducida y posteriormente se disolvió en acetato de etilo y se lavó por triplicado con un embudo de separación con ácido clorhídrico al $1 \%$ y después con carbonato de sodio al $1 \%$. Posterior- 
mente, el acetato de etilo se eliminó utilizando un rota vapor y el contenido se extrajo con diclorometano, el cual se dejó evaporar por $24 \mathrm{~h}$. El extracto se obtuvo mediante raspado con una espátula y se almacenó en tubos de vidrio con tapón de rosca en oscuridad. El extracto se produjo por triplicado para cada cepa. La composición de cada extracto se caracterizó mediante espectrometría de masas en el laboratorio del Centro de Nanociencias y Micro y Nano Tecnologías del IPN.

\section{Bioensayos de actividad patogénica}

Para evaluar la actividad patogénica de las cepas, éstas se activaron en matraces de $250 \mathrm{~mL}$ con caldo dextrosa Sabouraud enriquecido con $1 \%$ de extracto de levadura y suplementado con $0.05 \%$ de estreptomicina. Los matraces se incubaron a $30^{\circ} \mathrm{C}$ y a $200 \mathrm{rpm}$ por $48 \mathrm{~h}$. Posteriormente, el inóculo se cultivó por difusión en cajas de Petri con el mismo medio. Las cajas se incubaron a temperatura ambiente durante 21 días para obtener las conidias. Las conidias se recuperaron mediante raspado con una asa Dirglaski y se depositaron en un frasco con Tween ${ }^{\circledast}$ al $0.05 \%$. La suspensión de conidias a utilizar se ajustó a una concentración de $1 \times 10^{7}$ conidias $/ \mathrm{mL}$. Para el bioensayo se utilizaron 25 larvas neonatas de cada especie con tres repeticiones y un control para dar un total de 100 larvas por tratamiento. Las larvas a utilizar se colocaron sobre un papel absorbente y se rociaron con la suspensión de conidias. Posteriormente, se tomaron con un pincel de pelo de camello y se colocaron individualmente en recipientes de plástico de $30 \mathrm{~mL}$ conteniendo $5 \mathrm{~mL}$ de dieta artificial. Los recipientes se taparon y se colocaron en bolsas de papel de estraza y se incubaron a $26^{\circ} \mathrm{C} \pm 1{ }^{\circ} \mathrm{C}$, fotoperiodo de $14: 10 \mathrm{~h}$ (luz: oscuridad) y $65 \% \pm 1 \%$ humedad relativa por siete días para evaluar el porcentaje de mortalidad. Los resultados se analizaron por ANOVA y comparación de medias utilizando la prueba de Tukey, $\mathrm{P} \leq 0.05$.

\section{Bioensayos de actividad tóxica}

Para evaluar la actividad tóxica del extracto se utilizó la técnica de micro-inyección. Se utilizaron larvas del tercer instar previamente sometidas a $0{ }^{\circ} \mathrm{C}$ por 5 min para adormecerlas. El extracto diluido en diclorometano al $5 \%$ se cargó en una micro-jeringa para inyección cromatográfica de $10 \mu \mathrm{L}$ (Agilent, Santa Clara, CA). La aguja se insertó en la parte posterior de la cápsula cefálica de la larva, entre la cabeza y el tórax, al inicio del primer segmento y se introdujo hasta el hemocele y se aplicaron $5 \mu \mathrm{L}$. El extracto se agregó a las concentraciones de $1 \mathrm{mg} / \mathrm{mL}, 0.5 \mathrm{mg} / \mathrm{mLy} 0.1 \mathrm{mg} / \mathrm{mL}$. El procedimiento se realizó utilizando un microscopio estereoscópico (Zeiss Stemi DV4, Oberkochen, Alemania). Después de la inyección, cada larva se colocó en un recipiente de plástico de $30 \mathrm{~mL}$ con $5 \mathrm{~mL}$ de dieta artificial y se incubó a $25^{\circ} \mathrm{C} \pm 1$ ${ }^{\circ} \mathrm{C}$, fotoperiodo de $14: 10 \mathrm{~h}$ (luz:oscuridad) y $65 \% \pm 1 \%$ de humedad relativa durante $24 \mathrm{~h}$. Cada extracto se consideró un tratamiento y se utilizaron diez larvas por tratamiento con tres repeticiones y un control. Los resultados fueron sometidos a un ANOVA y prueba de Tukey para comparación de medias con una $\mathrm{P} \leq 0.05$.

\section{RESULTADOS Y DISCUSIÓN}

En este estudio se observa que todas las cepas amplificaron la secuencia homóloga que codifica el dominio A que incorpora D-Hiv de la enniatina sintetasa de F. equiseti (Figura 1 A). Las PCR anidadas mostraron la presencia de los genes BbBEAS (Figura $1 \mathrm{~B}$ ) y bbBs/s (Figura $1 \mathrm{C}$ ) en todas las cepas, con excepción de la cepa 2857 que no posee el gen de la bassianolida sintetasa (Figura 1 C). La caracterización mediante espectrometría de masas (Figura 2) indicó que ninguna cepa produjo la beauvericina y la bassianolida fue producida únicamente por la cepa 1149. El espectro muestra un pico de 908.052 correspondiente al peso molecular de la bassianolida y no se observa ningún pico correspondiente a la beauvericina. El análisis de las secuencias confirmó que los genes amplificados corresponden a los genes BbBEAS y $b b B s / s$ (Figura 3 y Figura 4).

Los bioensayos de patogenicidad (Tabla 2) demostraron que existe diferencia significativa en la mortalidad causada por las diferentes cepas de B. bassiana tanto en S. exigua. $(F=3.265, \mathrm{gl}=14 / 30, \mathrm{P}<0.00)$ como en $S$. frugiperda $(F=$ $3.602, \mathrm{gl}=10 / 21, \mathrm{P}<0.00$ ). Los valores mayores de mortalidad fueron de alrededor de $44 \%$ sólo en S. frugiperda y fueron causados por las cepas 1512, 2253 y 2857. Los bioensayos de actividad tóxica realizados con el extracto de la cepa 1149 indicaron que existe diferencia significativa en la actividad tóxica del extracto inyectado a diferentes concentraciones tanto en S. exigua ( $\mathrm{F}=10.250, \mathrm{gl}=3 / 11, \mathrm{P} \leq 0.004)$ como en $\mathrm{S}$. frugiperda $(\mathrm{F}=3.583, \mathrm{gl}=3 / 11, \mathrm{P} \leq 0.066)$, siendo el extracto a la concentración de $1 \mathrm{mg} / \mathrm{ml}$ el de mayor actividad (Tabla 3).

No obstante la presencia de estos genes, las cepas no produjeron beauvericina y con excepción de la cepa 1149 ninguna otra produjo la bassianolida. Es posible que estos metabolitos no se hayan producido por las condiciones de cultivo a las que fueron sometidas, no obstante a ser las indicadas por Xu et al. (2007) para la producción de estos metabolitos secundarios y recomendadas por otros autores para Beauveria y otros hongos productores de beauvericina (Luangsa-ard et al., 2009; Bunyapaiboonsri et al., 2011), o que el proceso de extracción no haya sido eficiente (Xu et al., 2009a).

Con relación a la actividad patogénica, la mortalidad causada por las conidias de las cepas de estudio fue estadísticamente igual para S. exigua y estadísticamente diferente en S. frugiperda. No obstante, en ningún caso la mortalidad superó el $50 \%$, por lo que estos valores de mortalidad son irrelevantes para el control biológico de estas plagas. La actividad patogénica de la cepa 1149 en S. exigua, no mostró diferencia significativa con respecto a la actividad del resto de las cepas que no produjeron bassianolida. Para el caso de S. frugiperda, esta misma cepa causó una mortalidad estadísticamente igual a la de las cepas 1315, 3289, y 5649 y una mortalidad significativamente menor que las cepas 1512, 2253, y 2857 siendo que esta última no alberga el gen de la bassianolida y ninguna de ellas produjo este metabolito.

La mortalidad causada por el extracto de la cepa 1149 a la concentración alta $(1 \mathrm{mg} / \mathrm{mL})$ causó una mortalidad 


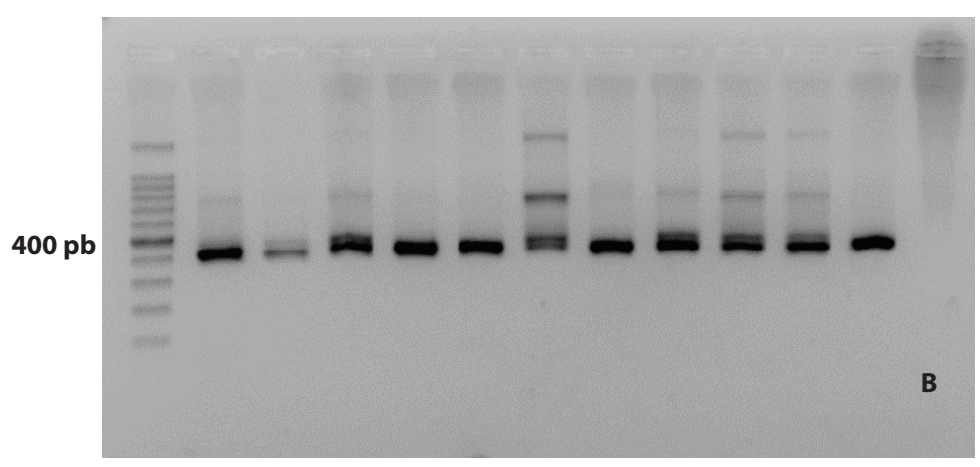

Figura 1. A) Amplificación de secuencias homólogas del dominio A de los genes de sintetasa en cepas de Beauveria bassiana utilizando el par de oligonucleótidos EA1F y EA1R. 1) Perfect DNA 100 pb Ladder, 2) ARSEF1118, 3) ARSEF1315, 4) ARSEF1512, 5) ARSEF1627, 6) ARSEF2857, 7) ARSEF3289, 8) ARSEF5649, 9) Bb1149, 10) Bb2253, 11) Bb3288, 12) Control negativo (CHE 237 Metarizhium anisopliae). B) Amplificación por PCR anidada del gen de la beauvericina sintetasa en cepas de Beauveria bassiana.C) Amplificación por PCR anidada del gen de la bassianolida sintetasa en cepas de Beauveria bassiana. Para B y C: Carril 1, MM 100 pb (Promega); carril 2) ARSEF1118; carril 3) ARSEF1315; carril 4) ARSEF1512; carril 5) ARSEF1627; carril 6) ARSEF2857; carril 7) ARSEF3289; carril 8) ARSEF5649; carril 9) Bb1149; carril 10) Bb2253; carril 11) Bb3288; carril 12) GHA; carril 13) control negativo.

Figure 1. A) Amplification of A-domain-encoding sequences of synthetase genes in Beauveria bassiana strains with primers pair EA1F and EA1R. 1) Perfect DNA 100 pb Ladder, 2) ARSEF1118, 3) ARSEF1315, 4) ARSEF1512, 5) ARSEF 1627,6$)$ ARSEF2857, 7) ARSEF3289, 8) ARSEF5649, 9) Bb1149, 10) Bb2253, 11) Bb3288, 12) Negative control (CHE 237 Metarizhium anisopliae). B) Nested PCR amplification of beauvericin synthetase gene in B. bassiana strains. C) Nested PCR amplification of bassianolide synthetase gene in $B$. bassiana strains. B) and C): Lane 1, MM $100 \mathrm{pb}$ (Promega); lane 2) ARSEF1118; lane 3) ARSEF1315; lane 4) ARSEF1512; lane 5) ARSEF1627; lane 6) ARSEF2857; lane 7) ARSEF3289; lane 8) ARSEF5649; lane 9) Bb1149; lane 10) Bb2253; lane 11) Bb3288; lane 12) GHA; lane 13) negative control.

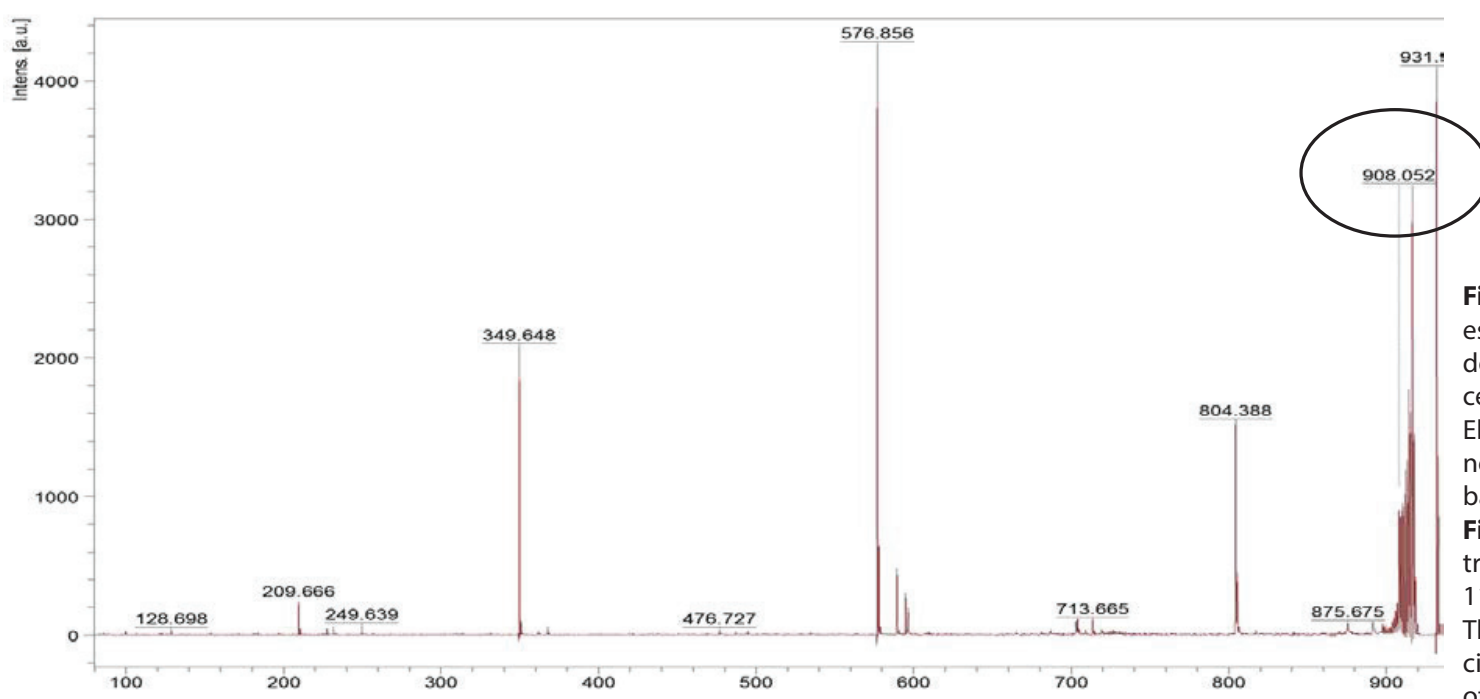

Figura 2. Análisis de espectrometría de masas del extracto micelial de la cepa 1149 de B. bassiana. El pico de 908.052 (círculo negro) indica la presencia de bassianolida.

Figure 2. Mass espectrometry analysis from $B$. bassiana 1149 strain mycelial extract The peak at 908.052 (black circle) indicates the presence of bassianolide.

\section{Volumen XXII, Número 3}




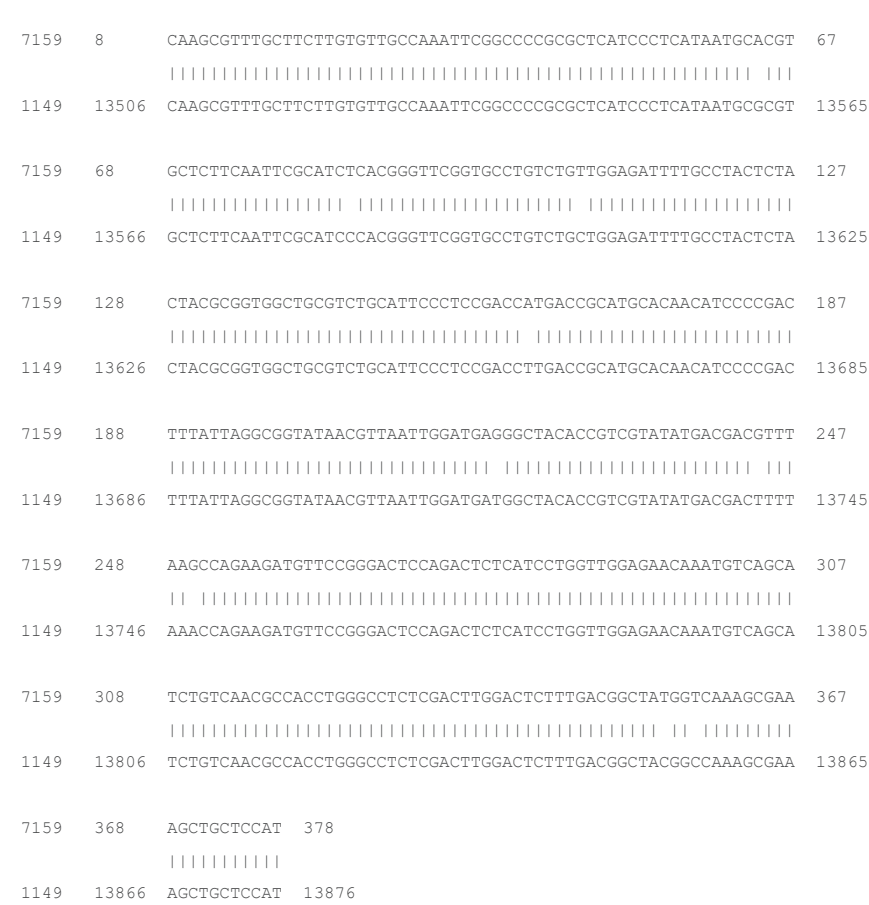

Figura 3. Alineamiento de la secuencia obtenida de la cepa ARSEF1149 con la secuencia completa del locus del gen biosintético de la beauvericina de la cepa de Beauveria bassiana ATCC 7159.

Figure 3. Sequence alignment from ARSEF1149 strain with the beauvericine biosynthetic gen locus complete sequence from Beauveria bassiana ATCC 7159.

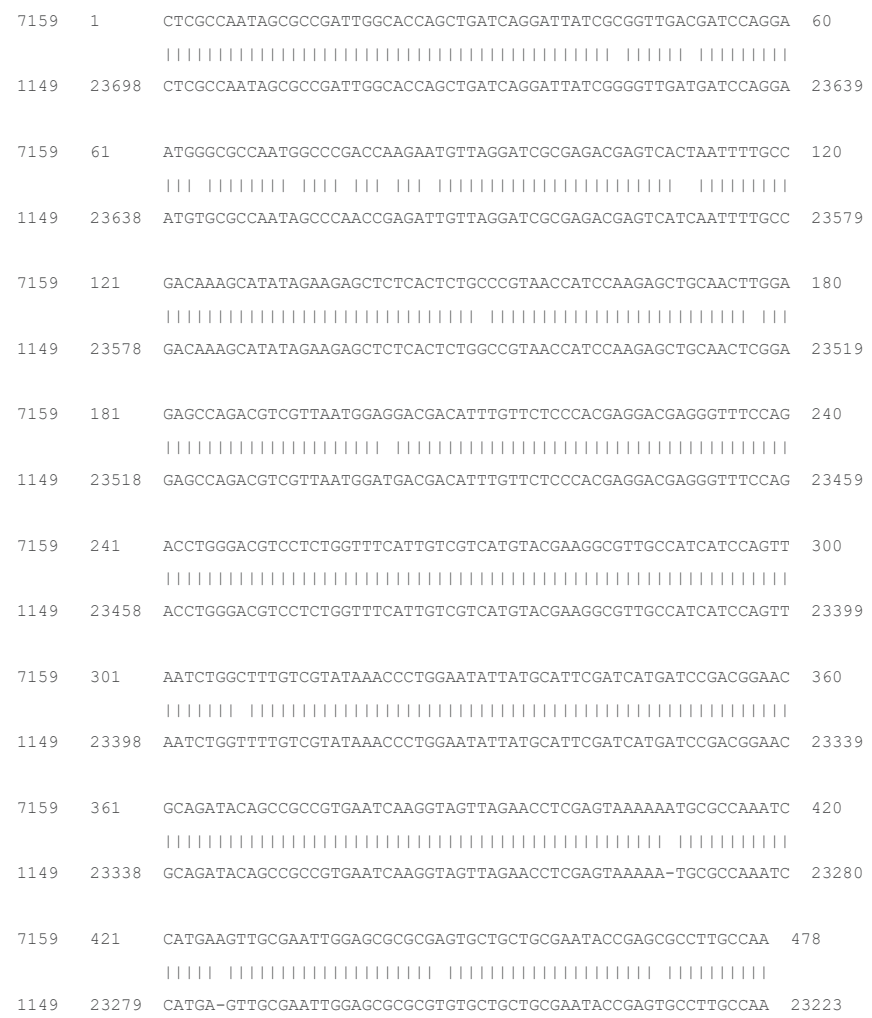

Figura 4. Alineamiento de la secuencia obtenida de la cepa ARSEF1149 con el locus del gen biosintético de la bassianolida de la cepa Beauveria bassiana ATCC 7159.

Figure 4. Sequence alignment from ARSEF1149 strain with the bassianolide biosynthetic gen locus from Beauveria bassiana ATCC 7159.

Tabla 2. Mortalidad de larvas de Spodoptera exigua y Spodoptera frugiperda causada por conidias de diferentes cepas de Beauveria bassiana.

Table 2. Spodoptera exigua and Spodoptera frugiperda larval mortality caused by conidia from different Beauveria bassiana strains.

\begin{tabular}{|lcc}
\hline Clave de la cepa & $\begin{array}{c}\text { Media de larvas } \\
\text { muertas de } S \text {. } \\
\text { exigua } \pm \mathrm{EE}\end{array}$ & $\begin{array}{c}\text { Media de larvas muertas } \\
\text { de } \text {. frugiperda } \pm \mathrm{EE}\end{array}$ \\
\hline 1118 & $10.67 \pm 3.528 \mathrm{ab}$ & $5.33 \pm 2.309 \mathrm{a}$ \\
\hline 1149 & $20.00 \pm 6.110 \mathrm{ab}$ & $28.00 \pm 10.583 \mathrm{ab}$ \\
\hline 1315 & $22.67 \pm 7.055 \mathrm{ab}$ & $34.67 \pm 19.732 \mathrm{ab}$ \\
\hline 1512 & $12.00 \pm 4.000 \mathrm{ab}$ & $46.67 \pm 8.327 \mathrm{~b}$ \\
\hline 1627 & $9.33 \pm 1.333 \mathrm{ab}$ & $\mathrm{ND}$ \\
\hline 2253 & $12.00 \pm 4.000 \mathrm{ab}$ & $42.67 \pm 6.110 \mathrm{~b}$ \\
\hline 2857 & $9.33 \pm 2.667 \mathrm{ab}$ & $44.00 \pm 5.657 \mathrm{~b}$ \\
\hline 3289 & $10.67 \pm 4.807 \mathrm{ab}$ & $22.67 \pm 15.144 \mathrm{ab}$ \\
\hline 3288 & $9.33 \pm 3.528 \mathrm{ab}$ & $\mathrm{ND}$ \\
\hline 5649 & $24.00 \pm 6.110 \mathrm{ab}$ & $13.33 \pm 12.858 \mathrm{ab}$ \\
\hline $\mathrm{Bb} 1$ & $5.33 \pm 1.333 \mathrm{a}$ & $16.00 \pm 4.000 \mathrm{ab}$ \\
\hline $\mathrm{Bb} 2$ & $9.33 \pm 1.333 \mathrm{ab}$ & $18.67 \pm 15.144 \mathrm{ab}$ \\
\hline $\mathrm{Bb} 3$ & $9.33 \pm 1.333 \mathrm{ab}$ & $25.33 \pm 16.166 \mathrm{ab}$ \\
\hline $\mathrm{BB} 4$ & $30.67 \pm 5.812 \mathrm{~b}$ & $\mathrm{ND}$ \\
\hline 3019 & $22.67 \pm 1.333 \mathrm{ab}$ & -- \\
\hline
\end{tabular}

$\mathrm{N}=30$. Las cepas Bb1, Bb2, Bb3, Bb4, y 3019 se utilizaron como control. Valores en una columna con la misma letra no tienen diferencia significativa, Tukey $\leq 0.05$. ND $=$ No determinado.

Tabla 3. Mortalidad causada por el extracto de la cepa 1149 de Beauveria bassiana en larvas de Spodoptera exigua y Spodoptera frugiperda.

Table 3. Mortality caused by Beauveria bassiana 1149 strain extract in Spodoptera exigua and Spodoptera frugiperda larvae.

\begin{tabular}{lcc}
\hline $\begin{array}{l}\text { Concentración } \\
(\mathbf{m g} / \mathrm{mL})\end{array}$ & $\begin{array}{c}\text { Número medio de } \\
\text { larvas muertas } \pm \mathrm{EE} \text { de } \\
\text { S. exigua }\end{array}$ & $\begin{array}{c}\text { Número medio de } \\
\text { larvas muertas } \pm \mathrm{EE} \text { de } \\
\text { S. frugiperda }\end{array}$ \\
\hline 0.00 & $3.33 \pm 3.33 \mathrm{~b}$ & $6.67 \pm 3.33 \mathrm{~b}$ \\
\hline 0.01 & $6.67 \pm 3.33 \mathrm{~b}$ & $3.33 \pm 3.33 \mathrm{~b}$ \\
\hline 0.05 & $6.67 \pm 3.33 \mathrm{~b}$ & $3.33 \pm 3.33 \mathrm{~b}$ \\
\hline 1.00 & $26.67 \pm 3.33 \mathrm{a}$ & $16.67 \pm 3.33 \mathrm{a}$ \\
\hline
\end{tabular}

significativa con respecto a las concentraciones media y baja, pero irrelevante para efectos en el control biológico de estas plagas.

Algunos estudios indican que la beauvericina actúa como un transportador de iones de calcio, potasio, litio, cesio y sodio (Prince et al., 1974), y que su modo de acción involucra una interacción con la membrana celular que incrementa la concentraciones de los iones $\mathrm{Ca}^{+2}$. Esta interacción provoca un daño a la membrana que permite el paso de la beauvericina de tal manera que puede tener contacto con el DNA formando agregados de oligonucleótidos-beauvericina lo que causa fragmentación del DNA (Pócsfalvi et al., 1997). Mallebrera et al. (2018) han considerado a la beauvericina como un agente insecticida, los estudios realizados a la fecha son pocos y los resultados derivados son variables.

Grove y Pople (1980) determinaron que la beauvericina causó una alta mortalidad en Aedes aegypti (86 \%), 
sin embargo, también determinaron que la mortalidad en Calliphora erythrocephala no fue significativa. Inclusive Fornelli et al. (2004) no encontraron toxicidad significativa de este compuesto en una línea celular de S. frugiperda. De acuerdo a Ganassi et al. (2002) la beauvericina administrada por ingestión a Schizaphis graminum causa una disminución significativa en el número medio de la progenie pero no afecta la sobrevivencia.

En este estudio, es posible que los bajos niveles de mortalidad estén asociados a la ausencia de la beauvericina, pero también es posible que la actividad del hongo esté más relacionada a la susceptibilidad del insecto que con la producción de estos metabolitos.

Con relación a la bassianolida, según Ravindran et al. (2018) este compuesto tiene actividad inmunosupresora en el insecto, debido a la interacción que ocurre entre las proteínas de defensa tipo CD22 de las células B (receptor) y el compuesto tóxico (ligando). Esta interacción incrementa la energía de unión y la estabilidad térmica de la bassianolida. Así mismo demostraron que la bassianolida causó una mortalidad superior al $80 \%$ por ingestión en larvas de Plutella xylostella, y de acuerdo con Xu et al. (2009b) la bassianolida fue un factor de virulencia altamente significativo en larvas de los lepidópteros Galleria mellonella, Spodoptera exigua y Helicoverpa zea. No obstante a que se han obtenido buenos resultados en otros estudios, en este trabajo la producción de bassianolida por la cepa 1149 no marcó una diferencia en la actividad con relación a las cepas que no produjeron este compuesto.

De acuerdo a Al Khoury et al. (2019) la expresión de los genes asociados a la síntesis de estos metabolitos, ocurre en diferentes etapas del proceso de infección y depende del modo de inducción y represión. Esto significa que se requieren más estudios para determinar si estos genes se expresan principalmente durante el proceso patogénico y si la actividad tóxica de estos compuestos está directamente relacionada con la susceptibilidad del insecto, o sólo se expresan como una respuesta de adaptación a su ambiente.

\section{CONCLUSIONES}

Las cepas de $B$. bassiana analizadas en este estudio albergan los dos genes productores de los péptidos no ribosomales beauvericina y bassianolida, con excepción de la cepa 2857 que sólo alberga el gen de la beauvericina. Estos compuestos son metabolitos secundarios que se han considerado como factores de virulencia en éste y otros hongos. No obstante que las cepas albergan estos genes, ninguna de ellas sintetizó la beauvericina, con las condiciones experimentales utilizadas, y sólo la cepa 1149 sintetizó la bassianolida. La capacidad patogénica de todas las cepas causó menos del $50 \%$ de mortalidad en larvas de S. exigua y S. frugiperda y la capacidad tóxica del extracto conteniendo la bassianolida causó una mortalidad inferior al $30 \%$. Se observan variaciones en las capacidades patogénica y tóxica de estas cepas, así como en la producción de estos metabolitos, por lo que es imprescindible la realización de estudios adi- cionales para confirmar la verdadera participación de estos compuestos en el proceso patogénico de B. bassiana.

\section{AGRADECIMIENTOS}

Agradecemos a la Secretaría de Investigación y Posgrado por el apoyo económico y al Centro de Nanociencias y Micro y Nanotecnologías por su apoyo en el análisis de los metabolitos secundarios ambos del Instituto Politécnico Nacional. Agradecemos al ARSEF por la donación de las cepas de Beauveria bassiana y al Centro Nacional de Referencia de Control Biológico por proporcionar la cepa CHE 237 de Metarhizium anisopliae.

\section{REFERENCIAS}

Al Khoury, C., Nemer, G., Guillot, J., Abdel Nour, A. y Nemer, N. 2019. Expression analysis of the genes involved in the virulence of Beauveria bassiana. Agri Gene. 14: 100094.

Bunyapaiboonsri, T., Yoiprommarat, S., Srisanoh, U., Choowong, W., Tasanathai, K., Hywel-Jones, N.L., Luangsa-ard, J.J. e Isaka, M. 2011. Isariotins $G-J$ from cultures of the Lepidoptera pathogenic fungus Isaria tenuipes. Phytochemistry Letters. 4: 283-286.

Feng, M.G., Poprawsky, T.J. y Khachatourians, G. G. 1994. Production, formulation and application of the entomopathogenic fungus Beauveria bassiana for insect control: Current status. Biocontrol Science and Technology. 4: 3-34.

Fornelli, F., Minervini, F. y Logrieco, A. 2004. Cytotoxicity of fungal metabolites to lepidopteran (Spodoptera frugiperda) cell line (SF-9). Journal of Invertebrate Pathology. 85: 74-79.

Ganassi, S., Moretti, A., Bonvicini Pagliai, M.A., Logrieco, A. y Sabatini, M.A. 2002. Effects of beauvericin on Schizaphis graminum (Aphididae). Journal of Invertebrate Pathology. 80: 90-96.

Gibson, D.M., Donzelli, B.G.G., Krasnoff, S.B. y Keyhani, N.O. 2014. Discovering the secondary metabolite potential encoded within entomopathogenic fungi. Natural Product Reports. 21: 1287-1305.

Grove, J.F.y Pople, M. 1980. The insecticidal activity of beauvericin and the enniatin complex. Mycopathologia. 70: 103-105.

Luangsa-ard, J.J., Berkaew, P., Ridkaew, R., Hywel-Jones, N.L. e Isaka, M. 2009. A beauvericin hot spot in the genus Isaria. Mycological Research. 113: 1389-1395.

Mallebrera, B., Prosperini, A., Font, G. y Ruiz, M.J. 2018. In vitro mechanisms of beauvericin toxicity: $A$ review. Food and Chemical Toxicology. 111: 537-545.

Molnár, I., Gibson, D.M. y Krasnoff, S.B. 2010. Secondary metabolites from entomopathogenic fungi Hypocrealean fungi. Natural Product Reports. 27: 1241-1275.

Pócsfalvi, G., Di Landa, G., Ferranti, P., Ritieni, A., Randazzo, G. y Malorni, A. 1997. Observation of non-covalent interactions between beauvericin and oligonucleotides using electrospray ionization mass spectrometry. Rapid Communications in Mass Spectrometry. 11: 265-272.

Prince, R.C., Crofts, A.R. y Steinrauf, L.K. 1974. A comparison of beauvericin, enniatin and valinomycin as calcium transporting agents in liposomes and chromatophores. Biochemical and Biophysical Research Communications. 59: 697-703. 
Raeder, U. y Broda, P. 1985. Rapid preparation of DNA from filamentous fungi. Letters in Applied Microbiology. 1: 17-20.

Ravindran, K., Sivaramakrishnan, S., Hussain, M., Dash, C.K., Bamisile, B.S., Qasim, M. y Liande, W. 2018. Investigation and molecular docking studies of bassianolide from Lecanicillium lecanii against Plutella xylostella (Lepidoptera: Plutellidae). Comparative Biochemistry and Physiology Part C: Toxicology \& Pharmacology. 206-207: 65-72.

Singh, H.B., Keswani, C., Ray, S., Yadav, S.K., Singh, S.P., Singh, S. y Sarma, B.K. 2015. Beauveria bassiana: Biocontrol beyond lepidopteran pests. En: Biocontrol of Lepidopteran Pests. K.S. Sree y A. Varma (ed.), pp. 219-235. Springer International Publishing, Switzerland.

Xu, L.-J., Liu, Y.-S., Zhou, L.-G., y Wu, J.-Y. 2009a. Enhanced beauvericin production with in situ adsorption in mycelial liquid culture of Fusarium redolens Dzf2. Process Biochemistry. 44: 1063-1067.
Xu, Y., Orozco, R., Wijeratne, E.M.K., Espinosa-Artiles, P., Gunatilaka, A.A.L., Stock, S.P., y Molnár, I. 2009b. Biosynthesis of the cyclooligomer depsipeptide bassianolide, an insecticidal virulence factor of Beauveria bassiana. Fungal Genetics and Biology. 46: 353-364.

Xu, Y., Orozco, R., Wijeratne, E.M.K., Gunatilaka, A.A.L., Stock, S.P., y Molnár, I. 2008. Biosynthesis of the cyclooligomer depsipeptide beauvericin, a virulence factor of the entomopathogenic fungus Beauveria bassiana. Chemistry and Biology. 15: 898-907.

Xu, Y., Zhan, J., Wijeratne, E.M.K., Burns, A.M., Gunatilaka, A.A.L. y Molnár, I. 2007. Cytotoxic and antihaptotactic beauvericin analogs from precursor-directed biosynthesis with the insect pathogen Beauveria bassiana ATCC7159. Journal of Natural Products. 70: 1467-1471. 